\title{
THE VOICES OF PIGEONS REGARDED AS A MEANS OF SOCIAL CONTROL
}

\author{
PROFESSOR WALLACE CRAIG \\ University of Maine
}

\section{INTRODUCTION}

Darwin's theory of sexual selection is the most important theory ever invented to account for the songs of birds. The idea of sexual selection has been enlarged somewhat by Groos and Haecker and others, and it is held, in one form or another, by almost all writers who are really acquainted with the habits of birds. But even those who accept the theory must feel that it is far from sufficient to account for the facts; and those who oppose it have never attempted to set up any positive explanation in place of it. Thus there is a pretty general feeling that something more is needed to account for the development of bird songs.

The writer has been studying this question for some years, with the privilege of using the large collection of living pigeons kept by Professor Whitman. ${ }^{1}$ I hope to bring out within a year or so a book on the subject, but it seems best to give this brief preliminary statement at the present time.

The great fact to be brought out is, that the utility of the voice in birds (pigeons) is of very much wider scope than has ever been suspected. The voice is a means of social control: that is to say, the voice is a means of influencing the behavior of individuals so as to bring them into co-operation, one with another. Naturalists have taken for granted that, to account for the social activities of animals and for their working together in harmony, it is sufficient to show that each individual

${ }^{1}$ I cannot too strongly express my thanks to Professor Whitman for his constant, generous, and invaluable aid, and for the example of his own work in the study of animal behavior. I am much indebted, also, to Professor G. H. Mead and Professor W. I. Thomas for reading this MS before going to press. 
is equipped with a set of social instincts. But it must be remembered that the same view was held until recent years with regard to human society, and that sociologists have now found it altogether untenable.

It is a common delusion that order is to be explained by the person's inherited equipment for good conduct, rather than by any control that society exercises over him. Once it was held that normal human beings are born with a set of commandments etched upon the soul.... Then came the charming tales of the mutual aid of ants, beavers, and prairie dogs, suggesting the existence of certain social instincts which moralists found it very convenient to use in explaining human society. We are not yet sure, however, that man is the "good ape" Buffon supposed him to be."

Neither is a bird the good machine that naturalists have supposed it to be. No internal machinery, no system of instincts, be it ever so perfect, could carry an individual dove through the vicissitudes of social life without the agency of social control. Of course I do not mean to deny that the behavior of the birds is instinctive: what is meant is, that to treat the behavior as instinctive is to give it an inadequate description. The inadequacy consists in studying the birds as individuals, and in treating the individual as a distinct entity. What is needed is, to transcend this individualistic view-point, and to see that the instincts of the individual can effect their purposes only when they are guided and regulated by influences from other individuals. In a complete explanation of animal society, therefore, the account of the social instincts must be supplemented by an account of the social influences by which the instincts of many individuals are brought into harmonious co-operation.

The reactions of the individual dove must be adjusted to meet the activities of many other birds-first its parents, later its mate, its young, its neighbors, and the strangers that come in its way. The activities of these other birds are endlessly diverse, and are changing from day to day and from hour to hour; the responses to the activities of these other birds must, accordingly, be adapted in each case to the immediate social situation. The adaptation to the immediate social situation

${ }^{2}$ Edward Alsworth Ross, Social Control (New York and London, I906), p. 5. 
must in many cases be exceedingly delicate, requiring that each individual be delicately susceptible to the influence of others. Most important of all, the individuals are free to change their positions in society. Individuals that are now treated with parental affection are later treated as outsiders. Those now regarded as strangers and enemies, may, after a period of familiarization, be accepted as members of the flock. Mated birds, after remaining absolutely faithful through a long period, may, under certain circumstances, separate, and one of them or each of them may form a new and different union. Now, if pigeon $\mathrm{A}$ can become for a time attached to pigeon $\mathrm{B}$, to the exclusion of all other possible mates; and if it can afterward become attached to pigeon $\mathrm{C}$, to the exclusion of all other possible mates; then it is evident that pigeon $\mathrm{A}$ must have been under some profound influence from pigeon $\mathrm{B}$, and again under a similarly profound influence from pigeon $\mathrm{C}$; such an influence of one bird over the behavior of another is social control.

The means of social control are various, including much more than the voice, not to speak of the song. The different utterances of the voice, the varying inflections of each of these utterances, the form and color of the body, the bowing, strutting, bristling of feathers, and all the expressions of emotion, are agencies potent to rouse and direct the activities of other birds. The nest, the eggs, and the young, when they come, are so many instruments for effecting social control. In the larger publication which is to follow, I shall endeavor to show what part is played by each of these agencies in particular. But my object in the present paper is merely to bring out the general truth, that the activities of pigeons are directed by social control, and that the voice is one means of such guidance.

The present paper, therefore, will be devoted to proving and illustrating the general principles set forth in this Introduction. The proving and illustrating will be done by a brief sketch of the social life of a dove; the blond ring-dove, the ring-dove commonly seen in cages, will be used as the type. The sketch of the social life of the dove will consist of three parts, treating respectively: I. Social Development of the Young; II. Social 
Life of Breeding Birds; III. Social Relations Outside of the Family.

\section{SOCIAL DEVELOPMENT OF THE YOUNG}

In the very act of breaking the shell of the egg and emerging therefrom, the young dove begins to exert control over its parents; for the movements of the young excite the parents, confirm their attachment to the nest and its contents, and stimulate them to secrete the "pigeons' milk" in the crop and to perform the feeding movements. The movements of the young are usually sufficient at first to stimulate the parents to give the requisite amount of food; but if the little one is allowed to become hungry it uses its voice, which, though feeble in tone, is strong in its effect upon the parents. For many days the young receive all their food from the parents. Then they begin to pick up food for themselves, but still continue to obtain part of their nourishment by persistent begging. The parents, however, become tired of feeding them, and the young must beg hard in order to stimulate them to give food; a young bird at this stage follows the old bird persistently, pushing its bill into his face, flapping its wings, sometimes striking the parent gently with one wing, and all the time squealing or piping. A young one which is not a persistent beggar may suffer from lack of nourishment, or may be compelled to seek all its own food at an earlier age than the normal. On the other hand, the duration of feeding by the parents may be under some circumstances greatly prolonged. Thus the whole matter of parental feeding is one of constant and delicate adjustment between parents and young.

The parents make no conscious efforts to educate the young. Nevertheless they educate them unconsciously in some very important matters. For example, the parents exhibit to the young the body-form, colors, gestures, and sounds characteristic of the species and thus the young learn to recognize their kind. Professor Whitman has proved this again and again by taking the eggs or young of wild species and giving them to the domestic ring-dove to foster, with the result that the young reared by the ring-doves have ever after associated with ring-doves and 
tried to mate with them. Passenger pigeons, for example, when reared by ring-doves, refuse to mate with their own species but mate with the species of the foster-parents. Hence we must believe that young doves have no inherited tendency to mate with birds of a particular kind; they learn to associate with a particular kind during the period when they are being fed, when the characteristics of their nursing-parents are vividly impressed upon their young minds.

The young doves have impressed upon their minds not only the characteristic marks of the species, but also the fact of differences between individuals. At first the two young doves (since there are nearly always two in each brood) are prone to beg food from each other as well as from the parents; but the facts that the nest-mate does not give food and that the parent does give food gradually lead the young dove to distinguish between the nest-mate and the parent. As the time of weaning draws near, the mother becomes unwilling to feed long before the father does so, and usually ceases to feed long before he ceases; this difference of behavior leads the young to distinguish between the two parents, and thus to add to their knowledge of individuality. Strange birds of the species may come near the young ones; the young may at first beg from these strangers, but the strange birds (under ordinary circumstances) refuse to feed them, and may even drive them off with blows; the young doves are thus familiarized with a further distinction of individuals. Thus a young bird which at first makes the most ludicrous blunders due to the confusion of individuals, gradually learns to make more numerous and finer distinctions until at length its perception of individual differences among doves is more delicate and more certain than can be attained by a human being. And it recognizes individuals not only by appearance, but also by voice.

Imitation as exhibited by young doves is only of the instinctive sort. Pigeons seem to be utterly devoid of that sort of imitation which is practiced by mocking-birds, parrots, and many other birds. It is an interesting fact that while the young dove learns to recognize the cooing of the species which nurses it, yet it does not learn to coo in the fashion which it has learned 
to recognize. A Geopelia which has been reared by ring-doves associates permanently with ring-doves and tries to mate with them; yet it coos and calls and bows precisely after the fashion of its ancestors, never learning either the music or the gestures of its adopted companions. This fact proves that doves do not imitate, in the sense of voluntary imitation. But instinctive imitation, or suggestion, they exhibit in a great variety of ways and with extreme sensitiveness. The cooing of one dove is enough to set the whole pigeonry to cooing. The sound of the alarm-note is enough to stop the cooing of the whole pigeonry at once. Pigeons may learn to eat a certain kind of food by seeing other birds eat it. ${ }^{3}$ And hungry birds may be guided to food by hearing other birds pecking. We shall see that suggestion becomes an agent of overwhelming power in the sexual life of mature birds. Suggestion and instinctive imitation are, all told, among the most constant and most potent agents of social control. And the voice is one of the most frequent excitants of instinctive imitation; the voice has immense suggestive power.

When a bird reaches the breeding age, it must have the influence of a bird of the opposite sex in order to complete its own development. Its equipment of breeding instincts is, to be sure, marvelously adapted to the complex processes of mating, nestbuilding, brooding, and feeding young. Yet these instincts seem to be at certain points incomplete, so that they need to be supplemented by experience; and even where not incomplete, they need a strong stimulus to set them going for the first time. If two inexperienced birds be allowed to mate, they are very slow in coming to the point of mating; and, though they go through all the processes of mating, nest-building, and brooding, yet their efforts lack something of the precision and the promptness which signally characterize the work of experienced birds. If, on the other hand, an inexperienced bird be paired with an old, experienced mate, it is noticeable that the old bird takes the lead in a great many of the operations, and the young bird is brought to the complete exercise of its functions much more p. $18 \mathrm{r}$.

${ }^{3}$ C. Lloyd Morgan, Habit and Instinct (London and New York, 1896), 
quickly than if it had had a mate as young as itself. We see thus that tradition is one of the means of social control. And the voice is a most important agent for carrying tradition.

\section{SOCIAL LIFE OF BREEDING BIRDS}

When ring-doves are pairing off preparatory to breeding, since there is no very evident difference in the appearance of the sexes, each dove must, by its behavior, proclaim its own sex and induce other birds to proclaim theirs. The male takes an aggressive attitude, and compels the female to submit to him. The female behaves in an enticing manner, and leads the male on. The influence which one bird exerts over another is powerful, as we may prove by the following experiment. Take a male of the normal degree of aggressiveness and clamorousness; put him in a cage alone, and put beside his cage another containing a male of an exceptionally aggressive and uproarious temper. The voice and gestures of the second male may in a short time subdue the first, compel him to stop his noisy effusion and his pompous strutting, nay, even constrain him to act like a female. Now, instead of experimenting with two males, suppose we similarly place a male and a female in separate cages beside one another. If the female has been long unmated, she may herself have become almost as aggressive as a male. But if the male that is now put beside her is ready to mate and plays up to her, he will quickly subdue her and cause a complete reversal of her character. The change is so complete that a man who has learned to know all his birds individually will find it hard to recognize the same female after such an alteration. The female exerts an influence over the male which is perhaps equally profound, but which is not usually so conspicuous. I have, however, seen a slow and indifferent male mourning-dove set on fire by one coo from the female. Anyone who has witnessed the mutual influence of the sexes in doves, and has appreciated the power of that influence and the profundity of its effects, can never again hold the theory that the voice of the dove is impotent and useless.

This reciprocal stimulation of the mating period has not 
only the immediate effect of rousing the mutual feelings of the two birds and uniting them to one another by an unbreakable bond. It has remote effects of great diversity and vast import, some of which I shall now indicate.

The union of a certain male with a certain female inhibits each of them from paying any attention to the sexual advances of other individuals. The two birds are remarkably faithful to one another so long as they remain mated. This faithfulness is not blind and inevitable, like the reputed faithfulness of an ant or a termite. For it may be terminated by the death of one party to the union, or by the passing of the breeding-season, or by other circumstances. In such cases the liberated bird or birds may afterward form new unions. This fact shows that so long as the two birds do remain united and faithful, they must be controlled by bonds which are potent not only to bind them to one another but also to make them regard with indifference the sexual behavior of their neighbors. One such bond is a daily and almost hourly communication of affection by means of voice, gesture, and mutual caresses.

The stimulation of pairing prompts the birds to seek a nesting-site and to construct a nest. This brings at once a new and important problem for social control. The two birds must be brought into agreement upon a nesting-site. They usually try a number of promising situations. Either bird, upon finding a likely spot, gives a nest-call which stimulates the mate to fly toward the source of the sound. (Now comes into useful operation the ability of the birds to recognize one another individually by sound of voice.) When at length a site is agreed upon, the selection is impressed upon the minds of the birds by a ceremony in which both sit together in the chosen spot and call and caress one another for a long period. Then one bird, usually the female, remains in the nest to build and fashion it, while the other bird flies off in search of building material. Each time the male returns with a straw, the female welcomes him with a low, complacent cooing and an affectionate flutter of the wings; which must serve to confirm still further the union of the birds and the choice of a nesting-site. The nest 
itself, by association with these ceremonies, becomes an instrument of social control; it acquires a power over the birds to hold them to their duties.

Copulation is preceded by a most elaborate ceremony. Groos attempts to explain this by a double theory which states: (I) That the act of copulation must be rendered difficult, in order that it may not be repeated to an injurious extent, and in order that the birds may gradually be made ready for the act. (2) That the means by which the act of copulation is rendered difficult is a special instinct of coyness in the female. This theory may perhaps be regarded as an adumbration of the truth. But there are many objections and difficulties. And there are two easily ascertained facts which are each sufficient to confute the theory. These facts are: (a) In some birds, notably the domestic fowl (also the "English" pheasant, and perhaps the whole pheasant family), copulation, though sometimes preceded by a slight ceremony, is in many cases effected by the male at will, without ceremony or check of any sort, showing that this mode of behavior is not necessarily a dangerous one, as Groos's theory assumes it to be. (b) In pigeons, amongwhich there is always a ceremony before pairing, the female sometimes is more anxious to mate than is the male, and leads the male on. The females of this group at least, certainly have no special instinct of coyness. They may in some cases show reluctance to accept the advances of the male, but these cases may be explained in the simplest manner. For in some of these cases the trouble is that the female is not yet ready to mate. In other cases the female may be ready to mate, but she has been made timid by contact with a miscellaneous group of birds, some of which are fighters; it is natural that such a female should at first be frightened by the advances of the male; this certainly does not show a special instinct of coyness.

The fact to be explained, then, is, that some birds, as the pigeons, invariably lead up to copulation with an elaborate ceremony; but other birds, as the domestic fowl, frequently copulate without such ceremony. If we contrast the habits of these two sorts of birds, we find that which will account for the ceremony. 
Copulation in the domestic fowl may be performed at almost any time; but copulation in pigeons has important time-relations which explain the whole matter, time-relations which I shall now describe in some detail.

In the first place, the sexual activity occurs at long intervals in the life of the dove-once in about four or five weeks throughout the breeding season. In the intervals both birds are normally destitute of the desire to pair. The elaborate preliminary ceremony is needed as a stimulus to bring both birds to the point of sexual activity.

In the second place, each time the birds unite in sexual activity they must be given the impetus to start a long, complex cycle of operations which may be summed up thus: Copulation continues for a few days; copulation ceases; the female lays two eggs; both birds begin at once to take regular turns in sitting on the eggs; after fourteen days of brooding, when the eggs hatch, both birds begin suddenly to secrete in the crop a food aptly called "pigeons' milk," and to perform reflexes peculiarly adapted to the feeding of the tiny young. The birds must go through the whole series of activities in order. If a male has been through the pairing activity, he is ready to sit; otherwise, he is not ready to sit. If he has been sitting on the eggs for fourteen days, he is ready to feed young; otherwise, he is not ready to feed young. And so with many other steps in the process, which cannot all be mentioned in this brief account. Now, the ceremony at the beginning evidently serves as a match which sets fire to this long train of stimuli. And when this train has burned to the end, the fire of another ceremony is needed to set off the train of the next brood.

In the third place, and most important of all, the whole series of changes mentioned in the last paragraph, in order to be successful, must occur in both birds at the same time. Each bird contains in its nervous system, not only a train of explosive material, ready to be touched off, but also an accurate I4-day chronometer; the male chronometer and the female chronometer must be wound up at the same time and set going synchronously, in order that the birds may enter synchronously upon the feeding 
of the young. Asynchronism may and sometimes does occur, and it may cause loss of eggs or of young. But the number of such accidents is reduced to a minimum by the fact that it difficult for either male or female to start any of the reproductive operations without the elaborate preliminary ceremony. In other words, it is difficult for either male or female to start any of the reproductive operations without the active co-operation of its mate. Whenever either bird is more ready than the other, the first bird is retarded by the influence of the second, and the second is accelerated by the influence of the first. Thus synchronization is effected by mutual adjustment, not by the adjustment of either bird exclusively.

The most remarkable fact in this time-adjustment is, that even the time of egg-laying on the part of the female is determined by the mutual activities of the two birds. The time of egg-laying is determined by all the preliminary operation, including the work upon the nest. Experiments show that the ceremony which accompanies copulation is one of the most important stimuli to oviposition. Even if the birds be prevented artificially from consummating the act of pairing, yet the ceremony of pairing is followed by the laying of the two eggs.

To sum up all that has been said with regard to the uses of the elaborate ceremonies of the pairing period: These uses are, (a) To bind together two birds as mates, and to inhibit in them all impulse to seek other mates; (b) To bring both birds into agreement upon a nesting-site, and to inhibit all impulse to use other nesting-sites; $(c)$ To rouse both birds to breeding activity, to start both synchronously upon the complex series of reproductive activities, even to determine the time at which the female shall lay her eggs.

As soon as the first egg is laid, a great change comes over both birds. This change is manifested in several ways-among others, in a comparative silence. This has usually been regarded as a merely negative change, a mere loss of voice; but there could not be a greater mistake. The silence is one of inhibition, not a mere lack of impulse; it is active, not passive; it is a silence suffused with strong emotion, not the silence of indiffer- 
ence. The teleology of the silence is obvious-it is to reduce the danger of the discovery of the nest by enemies. This silence, as I have said, is only relative; the birds feel one another's presence as much as during the pairing period, they still continue to communicate, though in subdued tones, when near the nest, and when away from the nest the male may sing as loudly as he does during the pairing period.

The doves continue, through the period of brooding and feeding the young, to exercise control over one another in a great variety of ways. They exhibit several new forms of social control which serve the new ends of brooding and feeding. But I must leave a complete account of these forms of social control to be given in the larger publication which is to follow.

In closing this brief account of the sociology of breeding birds, I wish to mention the preparation for a second (or third, fourth, etc.) brood. When the young are about ten days old, the exact time being very variable, the parents begin to prepare for a new parenthood, going through a ceremony very much like that which preceded the first brood. If it happens at this time that the male, for example, lacks energy to perform the ceremonies and rouse himself to the duties of a second brood, the female entices him for a long time, but finally, if he fails to respond, she deserts him and seeks another mate. This is an example of that individual freedom which shows us that doves are not so mechanically bound to their social duties as ants are reputed to be (p. 93), and that dove society can hold together and pass through its teleologic sequences only by means of social control (pp. 86-87).

\section{SOCIAL RELATIONS OUTSIDE OF THE FAMILY}

There is a great deal of contention among pigeons. But a contest is never decided by mere physical strength and prowess. Very rarely does a bird suffer serious injury in a fight. The vanquished is usually defeated simply because of the superior determination of the victor. Hostilities are accompanied or preceded by an elaborate ceremony of cooing and gesturing, and in a large proportion of cases this pantomime alone is sufficient 
to show which party to the quarrel is most determined, and to cause the other party to turn tail and flee wihout striking a blow.

Now, if one bird is much more determined than another, there is some reason for its being so. It may be defending its own territory against invasion by a stranger. Recently I put into the cage occupied by a small, young, timid female, a cruel tyrant of a male, whom I had taken away from his mate because he abused her; after a few seconds' exchange of blows between these two, the timid bird that "owned" the cage had that cruel male flying before her, offering no resistance to her vicious attacks upon him. Birds that own a nest with eggs or young are so determined in their manner that strangers dare not approach. A female regularly gives in to her mate, even though he may be cruel to her. If she is approached by other males, she suffers herself to be driven away from them by her jealous spouse. Professor Whitman tells me that even a female of the domestic pigeon, when mated with a male ring-dove (less than half her size), whom she could crush if she wanted to, gives in to her little husband with the same meekness that she would show toward a husband of her own species. But let the female be threatened, not by her own mate, but by a stranger, and she is changed at once from the lamb to the lion. That the female always yields to her mate is due to no severity on his part, for he is always restrained in his attacks upon her. Indeed, the male shows restraint even when quarreling with neighbors outside of his own family; for if they are birds with which he is familiar, he fights them with less fury than he would show toward an utter stranger. Many other examples could be given of what I must call the pigeon's sense of rights and duties. Psychologically this is surely very different from the human sense of rights and duties. But sociologically its working resembles the working of the sense of rights and duties in the mass of the human species. The few facts which I have given are sufficient to show that the contentions between pigeons are settled, not in accordance with the will of the strongest contestant, but in accordance with certain principles comparable to our principles of right and duty. And the settlement of a contest is 
often rendered still more merciful and more equitable by the fact that it is accomplished, not by blows, but by a vocal and pantomime ceremony.

\section{SUMMARY AND CONCLUDING REMARKS}

The organization of pigeon society is so flexible and adaptable that it cannot all be accounted for by reference to the instinctive machinery within each member of the society. Each dove is truly an individual, free to adapt itself to new conditions and thus to change its relations to society. For this reason, so long as an individual dove does maintain a fixed relation (such as that of mate), it does so by virtue of influences which society brings to bear upon it. That is to say, each dove is held in its place and held to its duties by social control. The song is one means of social control.

The uses of the song in social control are so numerous and so complexly interrelated that a complete list of them could not be made. I have drawn up the following partial list simply to give some notion of the diversity of the uses of the song.

I. Personal control, as that of the male over his mate.

2. Suggestion; as, the nest-call coo quickly brings the mate, the challenge coo causes the enemy to flee.

3. Stimulation; as, working up both male and female to the point of pairing, inducing oviposition in the female.

4. Inhibition; as, inhibiting adultery, inhibiting the use of nesting-sites other than the one chosen; inhibiting copulation out of the normal time.

5. Co-ordination in space; as, leading male and female to use the same nest.

6. Co-ordination in time; as, leading male and female to go through the brooding activities synchronously.

7. To proclaim: $(a)$ the bird's species; $(b)$ the bird's sex; (c) the bird's individual identity; ( $d$ ) the bird's rights (p. 98).

8. Tradition; as, when an experienced bird is mated with an inexperienced one, the former takes the lead (p. 9I).

It should be added that, while these and many other uses may be ascribed to the song, there are still other forms of 
social control served by utterances other than the song. For example, the voice of the young exerts a most powerful influence over the parent. The uses of the song are of the same general nature as the uses of other utterances, depending similarly upon the constitution of pigeon society and upon the susceptibility of the members of that society to control by the voices and gestures of their comrades. The song, therefore, ought never to be studied (as hitherto it has been studied) without reference to the whole system of vocal and gestural activity. And this system is of such magnitude that in the present paper I have not been able to mention all its details, much less to explain them.

Some of the pigeon's performances have been called ceremonies; this name has been applied, not carelessly, but after due consideration. The non-ceremonial vocal performances of pigeons are more like ordinary converse or communication; for they are used at any time, even upon the slightest stimuli, and they are accordingly simple, short and quick, and so flexible as to be changed this way and that according to the immediate circumstances. Those performances which I have called ceremonies, on the other hand, are reserved for more important occasions: they are highly elaborate, and accompanied by violent gestures or tense attitudes; they occupy a considerable time, often with a certain number of repetitions; and they have a fixed and definite form, which is not sacrificed to meet the petty circumstances of each occasion. These birdceremonies are more comparable to the elaborate ceremonies of some primitive peoples than to anything else in human sociology. Therefore, when naturalists witness the extravagance, the display of superabundant energy, in the songs of birds, let them not hastily conclude that the song is merely a vent by which surplus energy may go to waste; let them remember that similar extravagance appears in the human analogue of bird songs-the ceremonies of primitive peoples. Extravagance does not prove that savage ceremonies are usless, no more does it prove that bird songs are useless. 